\title{
Sierra Leone's Former Child Soldiers: A Follow-Up Study of Psychosocial Adjustment and Community Reintegration
}

\section{Citation}

Betancourt, Theresa Stichick, Ivelina Ivanova Borisova, Timothy Philip Williams, Robert T. Brennan, Theodore H. Whitfield, Marie De La Soudiere, John Williamson, and Stephen E. Gilman. 2010. “Sierra Leone's Former Child Soldiers: A Follow-Up Study of Psychosocial Adjustment and Community Reintegration." Child Development 81 (4) (July 15): 1077-1095. doi:10.1111/ j.1467-8624.2010.01455.x.

\section{Published Version}

doi:10.1111/j.1467-8624.2010.01455.x

\section{Permanent link}

http://nrs.harvard.edu/urn-3:HUL.InstRepos:26480445

\section{Terms of Use}

This article was downloaded from Harvard University's DASH repository, and is made available under the terms and conditions applicable to Other Posted Material, as set forth at http:// nrs.harvard.edu/urn-3:HUL.InstRepos:dash.current.terms-of-use\#LAA

\section{Share Your Story}

The Harvard community has made this article openly available.

Please share how this access benefits you. Submit a story.

Accessibility 


\title{
Sierra Leone's Former Child Soldiers: A Follow-up Study of Psychosocial Adjustment and Community Reintegration
}

\author{
Theresa Stichick Betancourt, Sc.D., M.A. ${ }^{1}$, Ivelina Ivanova Borisova, Ed.M. ${ }^{2}$, Timothy \\ Philip Williams, M.S.W., M.Sc. ${ }^{3}$, Robert T. Brennan, Ph.D., Ed.M., ${ }^{4}$, T. Hatch Whitfield, Sc.D. \\ 5 , Marie de la Soudiere, M.S.W. ${ }^{6}$, John Williamson, M.S.W. ${ }^{7}$, and Stephen E. Gilman, Sc.D. ${ }^{8}$ \\ 2 François-Xavier Bagnoud Center for Health and Human Rights, Harvard School of Public \\ Health, iib456@mail.harvard.edu \\ ${ }^{3}$ François-Xavier Bagnoud Center for Health and Human Rights, Harvard School of Public \\ Health, twilliams@post.harvard.edu \\ ${ }^{4}$ Department of Global Health and Social Medicine, Harvard Medical School, \\ Robert_Brennan@harvard.edu \\ ${ }^{5}$ Independent biostatistics consultant, hatch@verizon.net \\ 6 Independent consultant, UNICEF, marie.delasoudiere@gmail.com \\ ${ }^{7}$ Senior Technical Advisor for Displaced Children and Orphans Fund of USAID, \\ j.williamson@mindspring.com \\ 8 Departments of Society, Human Development \& Health and Epidemiology, Harvard School of \\ Public Health, sgilman@hsph.harvard.edu
}

\section{Abstract}

This is the first prospective study to investigate psychosocial adjustment in male and female former child soldiers ( $\mathrm{n}=156,12 \%$ female). The study began in Sierra Leone in 2002 and was designed to examine both risk and protective factors in psychosocial adjustment. Over the twoyear period of follow up, youth who had wounded or killed others during the war demonstrated increases in hostility. Youth who survived rape had higher levels of anxiety and hostility, but also demonstrated greater confidence and prosocial attitudes at follow up. Of the potential protective resources examined, improved community acceptance was associated with reduced depression at follow up and improved confidence and prosocial attitudes regardless of levels of violence exposure. Retention in school was also associated with greater prosocial attitudes.

\begin{abstract}
At present, Sierra Leone is still contending with the legacy of the 1991-2002 civil conflict involving the Revolutionary United Front (RUF), the Sierra Leonean Armed Forces Revolutionary Council (AFRC), the Sierra Leone Army (SLA), and local groups like the Civil Defense Forces (CDF). This bloody civil war led to human rights abuses, including mass mutilations and the pervasive use of children in armed conflict. Thousands of children, some as young as seven years old, were conscripted into fighting forces and paramilitary groups (Betancourt, Simmons et al., 2008; The World Revolution, 2001). Many young boys and girls were brutalized into submission, drugged and then forced to fight on the frontlines of combat; others who did not fight served as porters, cooks, guards, messengers, servants,
\end{abstract}

\footnotetext{
${ }^{1}$ Corresponding Author: Department of Global Health and Population / François-Xavier Bagnoud Center for Health and Human Rights, Harvard School of Public Health, 651 Huntington Avenue, 7th floor, Boston, MA 02115 USA, Tel: 617 432-5003; Fax: 617 432-4310; Theresa_Betancourt@harvard.edu
} 
human shields or bush "wives." While most point to abduction as their point of entry into their role as child soldiers (Mazurana \& Khristopher, 2004), some children may have assumed a more active role in their decision to participate in armed conflict. The breakdown of family and community systems, coupled with insufficient educational opportunities, left many children with limited viable options for the future (Ashby, 2002). Consequently, a militia group's promise of adventure, security, and camaraderie led some to turn to conscription into armed conflict as their 'best among the worst' of options (Machel, 2001; Peters \& Richards, 1998; Shepler, 2005). As a result of their involvement with armed forces and armed groups, many youth were witnesses and/or perpetrators of intense physical violence, including summary executions and death-squad killings, torture, detention, rape, bombings, forced displacement, destruction of homes, and massacres of family members. They were deprived of their rights to the care and protection of their families, and denied education and other developmental opportunities.

The Sierra Leone conflict involved direct attempts by rebel groups to destroy relations between young abductees and their families and communities. This was done by forcing many young people to commit atrocities (killings, assault) against loved ones and neighbors under threat of death. This violent indoctrination into fighting forces was intended to sever ties that might lead abducted youth to attempt escape and return home (Betancourt, Pochan et al., 2005; Wessells, 2005). Nevertheless, with the signing of the Abuja agreements in November 2000 and May 2001, most of Sierra Leone's former child soldiers began a long journey of return to their families and communities.

Disarmament, demobilization, and reintegration (DDR) refers to the process by which soldiers are returned to civilian life as conflicts end. DDR programs aimed specifically at child soldiers have been established in several countries, including Sierra Leone, where the National Center for Disarmament, Demobilization and Reintegration implemented a program of demobilization in conjunction with the United Nations Mission in Sierra Leone (UNAMSIL) and the warring parties (RUF, CDF, AFRC). These activities resulted in the demobilization of more than 72,000 combatants-including over 6,700 boys and girlsacross the country (National Committee for Demobilisation Disarmament and Reintegration, 2004; UNICEF, 2005).

The first step in DDR, disarmament, involves soldiers turning in their weapons, which are usually destroyed. The second step, demobilization, involves disbanding armed groups and releasing former child soldiers into civilian society. This step often includes family tracing in order to identify remaining family members or potential alternate caregivers for returning youth. The third phase, reintegration, is a much longer and more complex process. It is in this phase that psychosocial issues take center stage. Given direct attempts by armed forces to destroy relationships between abducted children and their families and communities, social reintegration remains a challenging issue in post-conflict Sierra Leone. To facilitate this process, sensitization campaigns were implemented to initiate local discussions about the reintegration of former child soldiers in the community. In addition, upon reunification, efforts were made to place children back into intact families, particularly families involving biological relatives (Betancourt, Pochan et al., 2005; Williamson, 2005). Although many organizations identified and trained community volunteers to provide monitoring and individual follow-up of resettled former child soldiers, no formal research has examined the social reintegration and psychosocial adjustment of these youth over time. The present study is intended to address these gaps.

\section{Child Soldiers: A Global View}

Despite a near universal condemnation from the international community (UNICEF, 2003) the use of child soldiers remains an ongoing reality in many modern armed conflicts. The 
2008 Child Soldiers Global Report documents the abduction and forceful conscription of children (both boys and girls) into government forces and armed groups in at least 86 countries to date (Coalition to Stop the Use of Child Soldiers, 2008). Since 2001, conflicts in Africa have involved the conscription of children into armed forces and armed groups including wars in Angola, Burundi, the Central African Republic, Chad, Cote d'Ivoire, the Democratic Republic of Congo, Guinea, Liberia, Rwanda, Sierra Leone, Somalia, and northern Uganda (Coalition to Stop the Use of Child Soldiers, 2004, 2008).

Child soldiers include boys and girls, many of whom are not fighters but are used in other ways. For these reasons, the 2007 Paris Principles established the definition of a child associated with an armed force or armed group as "any person below 18 years of age who is or who has been recruited or used by an armed force or armed group in any capacity, including but not limited to children, boys and girls, used as fighters, cooks, porters, messengers, spies or for sexual purposes. It does not only refer to a child who is taking or has taken a direct part in hostilities" (UNICEF, 2007, p. 7). The Paris Principles and other policy efforts have illuminated the child protection and rehabilitation issues central to addressing the problem of child soldiers globally. Experts contend that the term "children associated with armed forces and armed groups" (CAAFAG) is more accurate and captures the realities faced by children involved with armed groups and armed forces far beyond the proportion who actually engage as combatants (Betancourt, Borisova et al., 2008). For the purposes of the present study, we use the term "child soldier" for ease of readability with the caveat that we are implying the broader view involved in the use of the term CAAFAG.

\section{Psychosocial Adjustment and Social Reintegration of Former Child Soldiers}

Although the research on this topic is scant, war-related exposures and unsuccessful transitions into civilian life are thought to place former child soldiers at increased risk of mental health problems, re-recruitment, and many other forms of exploitation (Betancourt, Borisova et al., 2008; Betancourt, Pochan et al., 2005; Eyber \& Ager, 2003). Using various measures of psychosocial well-being and mental health, a handful of cross-sectional studies with former child soldiers have reported high levels of psychosocial problems relatively soon after reintegration. For instance, Allen and Schomerus (2006) collected data on a large $(\mathrm{n}=886)$ sample of former child soldiers under 18 in Uganda who had recently re-integrated into their communities. Although the study did not use standardized measures of mental health outcomes, high levels of psychological trauma and social difficulties were reported. Using the Impact of Event Scale-Revised (Weiss \& Marmar, 1997), Derulyn and colleagues (2004) documented high levels of symptoms (97\%) of post-traumatic stress disorder (PTSD) among 71 former child soldiers in northern Uganda. Among Ugandan and Congolese former child soldiers ( $\mathrm{n}=169)$, Bayer and colleagues (2007) found that more than one-third (34.9\%) met diagnostic criteria for PTSD. Similarly, Kohrt's (2007) study in Nepal found that children associated with fighting forces exhibited moderately higher psychosocial problems (aggression, depression, anxiety, and post-traumatic stress) as compared to never-associated children.

However, not all studies of former child soldiers document high rates of mental distress or disorders. For instance, Annan and colleagues' (2006) Survey of War-affected Youth (SWAY) in northern Uganda indicated that despite high rates of exposure to violence among male former child soldiers, levels of emotional distress were lower than might otherwise be expected. When compared to children never abducted by fighting forces, psychological problems among returning former child soldiers appeared mild to moderate, with serious distress concentrated in the minority of participants who experienced extreme violence (including perpetration of violence). In addition, the correlation between abduction and aggression was weak or nonexistent (Blattman \& Annan, 2007). Using retrospective reports, the SWAY study team found that even though some formerly abducted females reported 
difficulties with family and community acceptance upon return, a majority reported increased acceptance over time. The authors concluded that abduction itself was generally not a good predictor of mental health problems (Annan et al., 2008).

The studies of former child soldiers reviewed above involved data collection on samples relatively soon after demobilization or immediately following community reintegration. Only a handful of studies have assessed mental health and psychosocial functioning over time, addressing the potential long-term psychological consequences of involvement in armed forces and armed groups. Santacruz and Arana (2002) interviewed 239 former child soldiers who had belonged to armed groups in El Salvador nearly 10 years after the end of its civil war. At the time of these interviews, a majority of the sample continued to have vivid memories of war-related violence. Twenty percent suffered from constant insomnia and sixteen percent reported persistent nightmares. In addition, 39\% said that they felt tired and depressed quite often; 39\% reported problems with nervousness; and 37\% said they were easily annoyed and angered. This study highlights the potentially enduring difficulties faced by adults who were associated with armed groups as children.

To date, only one prospective longitudinal study of former child soldiers is available in the published literature. Boothby and colleagues followed a small cohort of male former child soldiers from Mozambique over a period of 16 years and outlined some of the long-term effects of child involvement with armed groups (Boothby et al., 2006). Overall, the results of this research suggest that a majority of the 39 young men studied made significant progress in returning to civilian life. However, none were able to fully escape their violent pasts. In 1988, while at the Lhanguene Rehabilitation Center in Mozambique, each young man in the sample reported experiencing recurrent thoughts and memories of traumatic events. Overall, symptoms of distress persisted 16 years later, but the proportion of former child soldiers experiencing problems as adults was considerably lower than those reporting these problems as children (Boothby, 2006). At the last point of assessment, 50\% of the participants reported emotional and physical reactions or symptoms indicative of traumatic stress reactions when reminded of hurtful or traumatic events. Additionally, the research indicated that longer length of time spent in the captivity of fighting forces seemed to augment risk of poor long-term social and emotional adjustment (Boothby, 2006). While the small sample size $(\mathrm{n}=39)$ of this study does not allow for in-depth statistical analyses, it does provide an important perspective into the long-term psychosocial consequences of child soldiering.

\section{Former Child Soldiers: An Interactive View of Resilience}

One of the questions of greatest interest regarding the well-being of former child soldiers is: how do these youth fare over time? Some surrender to the notion that these youth are a "lost generation," essentially too disturbed and violent to function productively, while on the other hand, some think these youth may represent a subset of resilient individuals who drew from personal strengths and external supports to survive a harrowing experience. A resilience perspective (Layne et al., 2007; Masten \& Obradovic, 2008; Rutter, 2006) provides a complex and integrated conceptual framework for thinking about post-traumatic adaptation in former child soldiers over time. Resilience is regarded as an interactive concept referring to "a relative resistance to environmental risk experiences, or the overcoming of stress or adversity" (Rutter, 2006, p. 2). The traumatic stress literature provides an integrative perspective on resilience and adaptation that is helpful for understanding the mental health of young people exposed to acute traumatic events such as armed conflict (Layne et al., 2007). Within the overarching framework of resilience, theories of stress accumulation and stress-adjustment offer complementary views for understanding former child soldiers' response to the compounded adversity characterizing their experience. 
Theories of stress accumulation posit that risk for poor mental health and developmental outcomes rises markedly with the accumulation of adverse life experiences (Dohrenwend \& Dohrenwend, 1974; Lazarus \& Folkman, 1984; Rutter et al., 2001; Thoits, 1991). A stress accumulation model suggests that children are profoundly affected through repeated and prolonged exposure to severe trauma or a series of stressful events that exceed an individual's threshold level of stress. Such exposure to stressful events can lead to a prolonged activation of biologically-based coping strategies, that when repeatedly activated, may compromise individuals' capacity to readjust, leaving them increasingly susceptible to physical or psychological problems throughout the life course (Dohrenwend \& Dohrenwend, 1974; McEwen, 2000; Worthman \& Panter-Brick, 2008). Particularly when these events occur early in life, the accumulation of such chronic or "toxic stressors" (National Scientific Council on the Developing Child, 2005) may limit the degree to which protective processes may be able to offset exposure to repetitive adversity (Beckett et al., 2006; Nelson et al., 2007; Smyke et al., 2007).

Resilience research has documented a number of protective processes that can help children achieve good functioning despite exposure to a range of difficult life circumstances (Luthar \& Goldstein, 2004). The stress adjustment paradigm (Lazarus \& Folkman, 1984) emphasizes the role of individual, familial and community resources in understanding the relationship between adverse life events/stressors and subsequent psychological adjustment and adaptation (Masten \& Obradovic, 2008). According to this framework, trauma, psychological adjustment, resilience, and the mental health of former child soldiers must be viewed as a dynamic process involving a number of ecological levels offering potential sources of protection (Bronfenbrenner, 1979) rather than solely individual characteristics (Betancourt \& Khan, 2008; Lazarus \& Folkman, 1984; Masten \& Obradovic, 2008).

Resilience theory and within it, theories of stress accumulation and stress adjustment, direct us to consider the complex interplay of risk and protective processes (Rutter, 2006), both during and after conflict, that likely shape the psychosocial outcomes and adjustment trajectories of former child soldiers. Young people associated with fighting forces may differ with regard to the frequency, duration and severity of their war experiences, as well as the accumulation of war-related stressors they experienced. Former child soldiers may also differ with regard to their post-war situations, particularly in terms of the family and community supports and resources available to them post conflict. Therefore, it is important to consider the accumulation and combination of both risk and protective factors in the lives of former child soldiers in order to better understand their long-term psychosocial adjustment (Betancourt, Borisova et al., 2008; Wessells, 2006).

On the basis of the existing evidence cited above, we are able to develop hypotheses regarding the influences of specific war-related exposures and potential post-conflict protective factors on the psychosocial well-being of former child soldiers. Exposure to violence is the most common risk during wartime (Annan et al., 2006; Bayer et al., 2007; Kohrt et al., 2008). Although most children affected by war experience high rates of exposure to violence (Barenbaum et al., 2004; Lustig et al., 2004), child soldiers are distinguished by experiencing particularly toxic forms of violence, often involving repeated personal victimization and in the most extreme cases, being forced to kill others (Coalition to Stop the Use of Child Soldiers, 2008). For example, in northern Uganda, Derluyn et al. (2004) observed very high rates of violent experiences with a majority of the sample reporting exposure to more than six traumatic events. Seventy-seven percent of the sample reported witnessing the killing of others, 35\% reported sexual abuse and 39\% of the sample reporting having killed others. 
Gender is an important factor shaping the war experiences of children associated with armed forces and armed groups. Females comprise a significant proportion of children involved with armed groups globally (McKay \& Mazurana, 2004). Although rape occurs among both male and female child soldiers (Annan et al., 2008; Betancourt, Borisova et al., 2008; Johnson et al., 2008; McKay \& Mazurana, 2004), sexual victimization presents particular challenges for psychosocial adjustment and social reintegration as female former child soldiers are often viewed as contaminated or sexually promiscuous (Betancourt, Simmons et al., 2008; Burman \& McKay, 2007; Coalition to Stop the Use of Child Soldiers, 2008; Mazurana \& Carlson, 2006; Mazurana \& McKay, 2003; McKay \& Mazurana, 2004; McKay et al., 2006).

Prior research has indicated that children who become involved with armed forces and armed groups at a younger age demonstrate greater adjustment difficulties later in life (Boothby, 2006). Furthermore, the length of time that a young person spends with armed groups may place them at greater risk for an accumulation of violence exposures as well as social and material deprivation (Betancourt, Borisova et al., 2008; Coalition to Stop the Use of Child Soldiers, 2008).

Sources of potential protection have also been documented in research on war-affected youth (Barenbaum et al., 2004; Betancourt \& Khan, 2008; Lustig et al., 2004). For child soldiers, acceptance from family members, peers and others in the community has been indicated as an important post-conflict determinant of psychosocial adjustment (Betancourt, Borisova et al., 2008; Betancourt, Simmons et al., 2008). For example, Annan, Blattman and Horton (2006) found that male former child soldiers reporting higher levels of family connectedness were likely to have lower levels of emotional distress and better social functioning. In some settings, community members may be open to accepting a child back despite his or her involvement with armed groups. In other situations, community members may view former child soldiers with fear and distrust due to atrocities committed during war time (Annan et al., 2006; Santacruz \& Arana, 2002). In Sierra Leone, despite sensitization campaigns in villages, a widespread initial community response was fear toward the returned child soldiers (Betancourt, Simmons et al., 2008). Collectively, these studies suggest that the degree to which community acceptance changes over time play an important ameliorative role for children at risk for poor adjustment given severe forms of war exposure.

Finally, sustained access to education remains an important consideration for the well-being of former child soldiers (Betancourt, Simmons et al., 2008; Machel, 1996). Opportunities to develop literacy and economic skills can aid in social reintegration of returning children and may act as a deterrent against re-recruitment (Alexander, 2006; Betancourt et al., 2008; Betancourt, Brewer et al., 2005; Sommers, 2003; Williamson, 2005). Schools may also serve as an important place to build positive social ties and a source of predictability in the lives of war-affected youth (Betancourt, 2005; Sommers, 2003). In this manner, it is possible that children with consistent school access may demonstrate improved psychosocial adjustment.

\section{Study Aims}

This study reports on the baseline and follow-up phases of a longitudinal study of former child soldiers in Sierra Leone. Consistent with a stress-accumulation approach, we hypothesized that psychosocial adjustment among former child soldiers would be associated with the degree of exposure to war violence, with the most detrimental effects among groups exposed to severe events (rape and killing). In examining hypotheses about stressadjustment, we also hypothesized that the presence of protective factors related to the individual (retention in school), family (family acceptance) and community (community 
acceptance) would be associated with improved psychosocial adjustment at follow up. We anticipated that the presence of protective factors indicative of social acceptance (family and community acceptance) would lead to better psychosocial outcomes, particularly among youth exposed to potentially stigmatizing war experiences (e.g., rape, killing).

\section{Method}

\section{Participants and Procedures}

This investigation was conducted in collaboration with the International Rescue Committee (IRC). Data collection began in 2002 with a baseline assessment (Time 1, T1) of 260 former child soldiers who had been affiliated with the Revolutionary United Front (RUF) in Sierra Leone. At the time, the IRC was a lead agency supporting DDR in several parts of the country. The initial sample for the study was obtained using a two-stage method of selection. First, IRC registries were pooled to create a master list of all youth who had been processed through Interim Care Centers at all sites in four districts of Sierra Leone during the most active period of demobilization, from June 2001 to February 2002 (n=260). All participants were between the ages of 10 and 18 at the time of selection and had been involved with the RUF's fighting forces. Exclusion criteria were inability to be interviewed due to a severe cognitive or physical disability as reported by program social workers (although no such cases were identified).

At follow up in 2004 (Time 2, T2), 60\% of the original sample was re-interviewed ( $\mathrm{n}=156)$. Midway through T2 data collection, the death of the IRC's country director and subsequent suspension of program activities halted completion of the follow-up survey. As a result, 31\% of the original sample was not re-contacted for follow-up. Of those T1 participants attempted for interviews at T2,1\% of caregivers declined consent for their child to participate, $1 \%$ of participants had died and $7 \%$ of the initial sample had relocated at a distance that prevented follow-up. Participants lost to follow-up did not differ significantly from ongoing participants in terms of age $(p=.74)$, gender ratio $(p=.60)$ or literacy levels $(p=$. 48). Higher percentages of completers versus non-completers ( $71 \%$ vs. $53 \%$ ) attended school at baseline ( $p=.002)$. Participants lost to follow-up reported similar levels of community acceptance at T1 $(p=.63)$. Ongoing participants did not differ from those lost to follow-up on depression $(p=.12)$, anxiety $(p=.29)$, hostility $(p=.14)$, prosocial attitudes $(p=$. $32)$ or confidence $(p=.96)$ as assessed at baseline. No significant differences were found between non-completers and ongoing participants in terms of age of abduction $(p=.19)$ or length of time with the fighting forces $(p=.45)$.

Data for all participants at T1 and T2 were collected through face-to-face interviews by a team of seven trained Sierra Leonean research assistants, monitored by the study PI and IRC staff at the country level. All research staff participated in a four-day training on interviewing procedures and ethical practices in working with vulnerable populations. The Sierra Leonean local research team and the study PI determined a process to best introduce the research to the community in a manner respectful of cultural norms about decisionmaking. First, the process of consent involved contact with village leaders and neighborhood meetings to introduce and explain the research. Second, local research assistants traveled to the target households with an IRC staff member. The study was then introduced and any questions answered in the local language, Krio, before a signature was given. All instructions and consents/assents were read aloud. Participants were informed of the general intent of the study and its longitudinal nature, including the intent to contact participants for future interviews. The parent/guardian informed consent and youth informed assent process were conducted separately. 
Due to a low literacy rate in the study population (50\%), all survey protocols were administered orally. The survey instrument, recruitment materials and the informed consent forms were constructed for easy comprehension and brevity. Visual aids were used to assist in the administration of Likert-type scales. The T1 assessments were approved by the IRC country program and headquarters staff; the $\mathrm{T} 2$ survey received Institutional Review Board (IRB) approval from Boston University School of Medicine/Boston Medical Center where the first author was based at the time. At baseline and follow-up, IRC social workers traveled with the research team to respond to cases requiring additional attention due to severe emotional or physical health needs.

In nonwestern contexts, such as Sierra Leone, the cultural validity of constructs measured remains a perennial challenge for cross-cultural research (Achenbach \& Rescorla, 2006; Canino \& Alegria, 2008). For these reasons, many of our measurement scales were developed in close consultation with local staff as well as focus group discussions among youth similar to the study population to determine the face validity and cultural relevance of survey items. All measures and questions were then forward- and back-translated to ensure accuracy. Similar combined methods for cross-cultural instrument development have been used in several recent studies of psychosocial adjustment of former child soldiers (Bayer et al., 2007; Kohrt et al., 2008).

This paper reports results for the sample of $n=156$ youth who were contacted at both the $\mathrm{T} 1$ and $\mathrm{T} 2$ waves of data collection. The average age at T1 in this sample of former child soldiers was 15.13 years, with $12 \%$ female and $88 \%$ male participants (Table 1). The sample was almost equally split in terms of religious background (53\% Christian and 47\% Muslim). At T1, 50\% of the sample reported poor literacy skills (reading and writing), with similar percentages of both girls and boys reporting poor literacy (53\% of girls and 50\% of boys); $72 \%$ of the youth were attending school at baseline and $65 \%$ were in school at the time of both interviews. At T1, the majority (83\%) of the youth reported staying with an immediate family member while $17 \%$ reported staying with an extended family or other caretaker; $84 \%$ of the female and $55 \%$ of the male caretakers were illiterate and reported no educational background.

\section{Measures}

War experiences-To assess individual exposures to severe forms of war violence, we used items from the Child War Trauma Questionnaire (CWTQ) (Macksoud \& Aber, 1996), initially developed for use with Lebanese war-affected youth. The questionnaire was adapted by our research team to better capture the context of the war in Sierra Leone; for example, items on bombing and shelling were removed and items on sexual assault and being forced to kill others were added. The adapted instrument contained 42 items regarding child's experience of war-related events. War experiences were coded for occurrence versus no occurrence because some traumas were experienced so commonly that participants had a difficult time accurately recalling or assessing frequency.

Three types of war experiences were examined in light of theory and research on the psychosocial adjustment of former child soldiers: 1) witnessing general war violence (e.g., massacres or raids on villages); 2) experiencing rape; and 3) perpetration of killing. We chose these categories because we were interested in exploring the particular effect of forms of severe violence common in former child soldiers. The survey instrument also included a self-reported age of abduction as well as duration of time with the fighting forces which were analyzed separately. 
Retention in school-A variable indicative of sustained access to education was created by comparing youth who reported being in school at both T1 and T2 to youth who were not in school at one or both waves of data collection.

Family acceptance-A measure of family acceptance was drawn from our previous qualitative work and consultations with local staff in 2002. The measure, only administered at $\mathrm{T} 2$, consisted of six items assessing the way former child soldiers perceived acceptance, understanding, and respect from their family members. Items were scored on a Likert scale with response options of "not true," "sometimes true" or "very true." Questions on this scale included "since the war you feel you are welcome in the family with whom you live," "you have the same opportunities and responsibilities as other children in the family/household," "your caregivers treat you as well as the other children in the household," etc. This measure exhibited strong internal reliability (Cronbach's $\alpha=.93$ ). At T2, reports of family acceptance were very skewed towards high values. As a result, the scale was dichotomized for statistical analyses (see below).

Community acceptance-A measure of community acceptance was drawn from our qualitative work and consultations with local staff in 2002. The measure consisted of six items assessing the way former child soldiers perceived acceptance from others in the community. Items were scored on a Likert scale with response options of "not true" to "sometimes true" or "very true." The measure included items such as "since the war, have people in this community been good to you?" and "since the war, you feel you have been welcomed back into the community where you live," etc. This measure was administered at both waves of data collection and exhibited strong internal reliability (Cronbach's $\alpha=.90$ at T1 and Cronbach's $\alpha=.89$ at T2). For each child, we computed a subscale score for community acceptance at $\mathrm{T} 1$ and $\mathrm{T} 2$. We also computed a "change in acceptance" by subtracting the T1 score from the score at T2. An increase in the community acceptance score between baseline and follow-up would thus indicate a positive change in community acceptance. Because change in community acceptance differed for those starting at higher or lower levels, all analyses were adjusted for T1 community acceptance.

Psychosocial Adjustment-To assess psychosocial adjustment, we used a measure developed by researchers at the Oxford Refugee Studies Program (MacMullin \& Loughry, 2004). This instrument was drawn from several standardized child mental health measures and was adapted for use among former child soldiers from Sierra Leone and northern Uganda using participatory methods (MacMullin \& Loughry, 2004). The measure contains 52 items: three subscales for mental health problems (anxiety, depression, hostility) and two subscales for positive/adaptive adjustment outcomes (confidence and prosocial attitudes). Each of the five domains is represented by a set of questions that inquires about specific behaviors particular to that domain (e.g., "Do you cry easily?" [Depression]; "Do you get into fights?" [Hostility]; and "Do you share with others?" [Prosocial Attitudes]). For each question responses were scored on a 1-4 scale, ranging from "never=1," "rarely=2," "sometimes=3" and "always=4."

Following our experience with using this measure at $\mathrm{T} 1$ in 2002, three items were excluded from the measure when it was re-administered at T2 in 2003-2004. Additionally, upon further analyses of T1 and T2 data, three more items were dropped because they did not contribute to the internal consistency of corresponding subscales. The 46-item version of this instrument had good internal consistency across all subscales at both waves of data collection. At follow-up, the Cronbach's $\alpha$ was .67 for the anxiety subscale ( 8 items); .70 for the depression subscale ( 8 items), .88 for the hostility subscale (12 items); .76 for the prosocial attitudes subscale (10 items) and .69 for the confidence subscale ( 8 items). For 
each child we computed a subscale score (e.g., anxiety, depression, hostility, prosocial attitudes and confidence) at $\mathrm{T} 1$ and $\mathrm{T} 2$.

Participant demographic characteristics-A demographic inventory collected information on gender, age and family socioeconomic resources. The measure of socioeconomic status was created to indicate an individual's access to food, housing, and clothing relative to others in the community. The measure consisted of four items and had a good internal consistency $(\alpha=.78)$.

\section{Statistical Analyses}

Statistical analysis of the data proceeded in three stages. First, descriptive statistics of study variables were analyzed. Summary statistics for continuous measures are reported as mean and standard deviation, while dichotomous measures are reported as percentages along with their associated counts.

Multiple imputation was then used to generate five complete datasets for the 156 participants in the baseline and follow-up interviews (Rubin, 1987). All remaining analyses were conducted using the multiply imputed datasets, and results were combined across imputations. This approach reduces bias to the extent that values on the observed variables are informative about values on items that were missing, increases precision relative to a complete case analysis with a smaller $N$, and accounts for the sampling variability across imputations (ibid). Imputed datasets were generated using the method of chained equations as implemented in IVEware (Raghunathan et al., 2001) and the results of analyses conducted across imputations were combined using the MIANALYZE procedure using the SAS software system, version 9.1 (SAS Institute Inc, 2004).

First, paired $t$-tests were used to compare values for psychosocial adjustment at T1 compared to T2. Second, correlation coefficients were calculated between all variables in order to inspect unadjusted, bivariate associations. Third, multiple linear regression was used to assess the effect of predictors on T2 psychosocial outcomes after adjusting for T1 scores and potential confounders. For each psychosocial outcome (depression, anxiety, hostility, confidence and prosocial attitudes), three main-effects regression models were fit, allowing assessment of the impact of introducing successive sets of covariates. The first model included only demographic factors (age, sex of child, SES) and baseline psychosocial adjustment scores. In the second model, dichotomous war experiences were added to the model to test the effects of stress accumulation. Model three added protective factors to the model to test hypotheses regarding stress adjustment. At each step we compared parameter estimates and model fits and calculated the difference in $\mathrm{R}^{2}$.

After assessing the main effects models, we tested whether or not the inclusion of interaction terms improved the overall model fit. Interactions were examined in conceptual groups testing first interactions between war exposures and protective factors. A second group of interactions were then tested examining interactions between gender and risk factors and then gender and protective factors on psychosocial outcomes. An F test using the TEST command in PROC MIANALYZE (SAS Institute Inc, 2004) was performed upon adding each conceptual group of interactions to the final main effects model (model 3 for each outcome) to test the joint hypothesis that the combined effect of the interactions did not differ from zero. If the $\mathrm{F}$ test was nonsignificant, no further individual testing of interactions was conducted to reduce risk of chance findings. If the $\mathrm{F}$ test indicated that interactions in the conceptual group improved the overall model fit, individual interactions were tested by adding them one-by-one to the final model for each outcome. 
All statistical analyses (two-tailed) were performed using the SAS software system, version 9.1 (SAS Institute Inc, 2004).

\section{Results}

\section{Exposure to Violence of Study Population}

The average age at abduction in this sample of former child soldiers was 10.51 years with no significant difference between males and females. Twelve percent of participants reported joining the fighting forces at very young ages (2-5 years), which likely reflects the fact that some children may have been abducted while with their mothers in the bush. Average length of abduction was 4.68 years with males and females reporting a similar duration of time in captivity with armed forces (Table 1). Nearly all (99\%) former child soldiers in the sample reported forced conscription (mainly through abduction).

All former child soldiers in the sample were exposed to high levels of violence. For example, $89 \%$ of females and $88 \%$ of males had witnessed some sort of war-related violence such as massacres or raids on villages. Being a victim of rape was reported by $37 \%$ of females and $6 \%$ of males in the sample. Perpetration of extreme acts of violence was reported by both males and females; $26 \%$ of females and $28 \%$ of males reported having killed either a stranger or loved one. Overall, $7 \%$ of youth reported experiencing all three exposures-witnessing mass violence, rape and wounding/killing others.

\section{Change in Psychosocial Outcomes}

Table 2 reports the results of the baseline and follow up assessments of each of the subscales on the measure of psychosocial adjustment. Average scores for the depression, hostility and anxiety subscales did not differ significantly between $\mathrm{T} 1$ and $\mathrm{T} 2$. In terms of the adaptive outcomes, confidence scores were similar between the two waves of assessment, yet average prosocial attitudes were lower at $\mathrm{T} 2$ compared to $\mathrm{T} 1$.

\section{Predictors of Psychosocial Outcomes: Correlational Analysis}

Bivariate correlations indicated expected patterns of covariation within and between variable domains (Table 3). The three subscales of mental health problems were positively intercorrelated as were the subscales for the two adaptive outcomes, confidence and prosocial attitudes $(r=.73)$. Higher levels of prosocial attitudes and confidence at T2 were correlated with symptoms of anxiety ( $r=.22$, and $r=.27$ respectively), but not other mental health problems.

Turning to cross-domain relations, we explored the relationship between the adjustment outcomes and two sets of predictors: 1) war-related risk factors (endorsing general witnessing of war violence, experiencing rape, perpetrating killing, length of time with the RUF and age of abduction); and 2) hypothesized protective factors (retention in school, community acceptance, family acceptance). Several of these variables were associated with T2 psychosocial outcomes.

War-related risk factors-Witnessing of general war-related violence was correlated with higher levels of hostility at T2 $(r=.24)$. Being abducted at a younger age and length of time spent with the fighting forces were not significantly correlated with any of the outcomes investigated. Experiencing rape during the war was associated with higher levels of hostility at T2 $(r=.37)$. In addition, rape was associated with higher levels of depression $(r=.25)$ and anxiety $(r=.31)$ at T2. Interestingly, rape was also associated with higher levels of prosocial behaviors $(r=.21)$ yet inversely correlated with staying in school $(r=-.21)$. 
Having killed someone during the war was associated with higher levels of depression ( $r=$ $21)$, anxiety ( $r=.26)$, and hostility $(r=.33)$.

Protective factors-Of the protective factors examined, family and community acceptance demonstrated promise as important psychosocial resources for the youth in our sample. Family acceptance was inversely correlated with depression $(r=-.33)$, anxiety $(r=-$. $22)$, hostility $(r=-.30)$, and positively correlated with prosocial attitudes $(r=.26)$ and confidence $(r=.23)$ at T2. Community acceptance was inversely correlated with hostility ( $r=$ $-.16)$ and positively correlated with prosocial attitudes $(r=.22)$ at T2. Retention in school was only marginally correlated with higher levels of prosocial attitudes and behaviors ( $r=$. $15)$.

\section{Predictors of Psychosocial Outcomes Over Time: Multiple Regression Analysis}

Three potentially confounding variables were examined to determine if they were associated with the variables of interest in this study: gender, age of child, and relative socioeconomic status (SES). Females in our sample were significantly more likely to experience rape ( $p \leq$. $0001)$. Our analyses also revealed that females had higher levels of hostility at T2 $(M=22.67$, $S D=4.67)$ compared to males in the sample $(\mathrm{M}=19.47, \mathrm{SD}=6.16, \mathrm{t}=2.12, \mathrm{p} \leq .05)$. Females and males reported comparable levels of depression and anxiety symptoms as well as confidence. Age of participants was correlated with age of abduction (with older participants in the sample being abducted at older ages). Older youth had significantly lower levels of family acceptance $(r=-.28, p \leq .001)$. Age was not significantly correlated with any other psychosocial outcomes investigated. Socioeconomic status was correlated with higher community acceptance at T2 $(r=.19, p \leq .05)$. Higher SES was also correlated with higher average levels of prosocial attitudes $(r=.22, p \leq .01)$ and confidence $(r=.25, p \leq .01)$. Therefore, gender, age and SES were entered as covariates in all regression analyses.

War-related violence and mental health adjustment-Table 4 displays regression analyses exploring levels of depression, anxiety, hostility, prosocial attitudes and confidence at follow up (T2). Adjusting for demographic variables and T1 scores, youth abducted into the fighting forces when they were younger $(\beta=-0.41, p \leq .05)$ were likely to report more symptoms of depression at $\mathrm{T} 2$. In examining the effects of stress accumulation, we observed that witnessing general violence, experiencing rape and having killed others during the war were not predictive of depression symptoms at $\mathrm{T} 2$, adjusting for all covariates.

None of the demographic variables investigated had an effect on anxiety level at T2. Witnessing general war-related violence was not a significant predictor of anxiety at follow up while being involved in wounding or killing others was only marginally significant in predicting symptoms of anxiety $(\beta=1.58, p \leq .10)$. Of all risk factors studied, surviving a rape was the strongest predictor of anxiety at T2 controlling for anxiety levels at T1 ( $\beta=4.06, p \leq$. 05 ) and adjusting for all other covariates. A history of having survived a rape contributed to an anxiety score more than half a standard deviation greater at follow up.

In terms of hostility, surviving a rape predicted significantly higher levels of hostility at $\mathrm{T} 2$ $(\beta=7.42, p \leq .001)$ such that surviving a rape contributed to a hostility score a full standard deviation greater at follow up upon adjusting for all other factors. A history of wounding or killing others ( $\beta=3.05, p \leq .05)$ was also associated with hostility scores nearly a half SD higher than the sample mean at follow up. These patterns were consistent when the protective factors were added to the model in Step 3. Length of time with armed groups and age of abduction were not significantly associated with levels of hostility at follow up (T2).

For adaptive outcomes, our analysis revealed that gender and socioeconomic status were both strong predictors of prosocial attitudes and confidence levels at follow up. In particular, 
females had significantly lower prosocial attitudes $(\beta=-3.13, p \leq .01)$ and confidence $(\beta=$ $-2.85, p \leq .05)$ at $\mathrm{T} 2$, while youth living in wealthier families reported increased levels of prosocial attitudes $(\beta=0.26, p \leq .05)$ and confidence $(\beta=0.34, p \leq .01)$. Neither general witnessing of violence nor a past history of wounding or killing others played a significant role in predicting levels of confidence or prosocial attitudes. However, survivors of rape demonstrated higher levels of both prosocial behaviors $(\beta=5.22, p \leq .001)$ and confidence at follow up $(\beta=3.40, p \leq .05)$.

\section{Individual, family, and community factors and psychosocial adjustment-}

Among the protective factors examined, staying in school and changes in community acceptance exerted the largest positive impact on psychosocial adjustment indicating their importance for facilitating stress adjustment in this setting. In particular, increases in community acceptance between $\mathrm{T} 1$ and $\mathrm{T} 2$ (adjusting for baseline community acceptance) were significantly associated with lower depression $(\beta=-0.35, p \leq .05)$, increased prosocial attitudes and behaviors $(\beta=0.62, p \leq .001)$ and increased confidence $(\beta=0.32, p \leq .05)$ at T2. Staying in school between T1 and T2 was predictive of greater prosocial attitudes at follow up $(\beta=1.55, p \leq .05)$. Although it did not reach the $\mathrm{p} \leq .05$ level of significance, perhaps in part due to $77 \%$ of subjects giving the highest possible rating on this scale, increased family acceptance demonstrated an inverse relationship with hostility $(\beta=-2.17, p \leq 10)$. None of the other protective covariates appeared to exert a positive effect on anxiety. None of the conceptual groups of interaction terms were found to significantly improve the fit of these final main effects models as assessed by joint $\mathrm{F}$ tests.

\section{Discussion}

In this analysis, we obtained partial support for both a risk accumulation and a stress adjustment model of psychosocial well-being among former child soldiers. We tested the association between exposure to war-related experiences of violence and psychosocial adjustment over a two-year period of follow-up. In addition we were interested in the role of protective factors at the individual, family, and community level in terms of their relationship with improved adjustment. Finally, we explored the potential mitigating impact of significant individual, family and community protective factors in the relationship between war experiences and psychosocial adjustment. Although average levels of depression, anxiety and hostility remained stable between baseline and follow-up, important changes were observed among a number of subgroups in the sample.

\section{War-Related Experiences and Mental Health Adjustment}

Although most children who survive wars are exposed to some degree of violence, our analyses indicated that two forms of violence common among former child soldiers-killing others and rape - had a particularly toxic influence on long-term psychosocial adjustment, particularly with regard to the outcomes of hostility and anxiety. These two categories of war traumas are set apart from the widespread witnessing of violence commonly reported among war-affected youth (Barenbaum et al., 2004; Lustig et al., 2004) by their intimate nature and intensity. However, research on child soldiers to date has not examined the specific longitudinal influence of these more severe forms of violence exposure.

Standard approaches to the measurement of war-related violence typically add all warrelated experiences into a single total exposure score. Such an approach may mask important dynamics related to the most severe forms of violence exposure, particularly those that distinguish the experiences of former child soldiers (Hatch \& Dohrenwend, 2007; Hundt et al., 2004; Netland, 2005). Our work builds on the work of Macksoud and Aber (1996) who developed the CWTQ to address the need to make qualitative distinctions between different types of war-related experiences faced by children and youth. Given the widespread trauma, 
violence and loss that characterize most war-affected young people, it is important to distinguish between forms of violence that are frightening — but widespread-from those that are less common - but distinctly toxic — in order to accurately identify those at risk for poor adjustment over time. It is important to note that witnessing of general war violence, although very common in this sample, was not a strong predictor of psychosocial adjustment over time. In contrast, the effects of experiencing rape and killing others were long lasting.

Of all the psychosocial outcomes investigated, the significant increases in hostility observed among youth who reported rape or killing are particularly concerning in that these exposures are much more likely to accumulate in child soldiers. Perpetration of killing was a significant predictor of hostility and remained a marginal predictor of anxiety even upon adjusting for all other variables examined in these analyses. The relationships we observed between extreme war experiences and these mental health problems are consistent with observations made in other studies of former child soldiers (Annan et al., 2006; Santacruz \& Arana, 2002) as well studies of adult war veterans (Hofmann et al., 2003; Maguen et al., 2006) and adult combatants in neighboring Liberia (Johnson et al., 2008).

Although the present analysis was limited by a small sample of females, gender was an important predictor of decreased prosocial attitudes and lower confidence over time. This finding likely indicates the "double indemnity" facing female former child soldiers in this context who were not only involved in violence perpetration, but frequently face greater stigma upon return home. Our qualitative data have indicated that female former child soldiers face increased risk of community stigma due to perceptions that sexual violation has "contaminated" them (Betancourt et al., 2008).

The finding in our data of an association between surviving a rape and increased confidence and prosocial attitudes was unexpected, but must be considered in light of the dynamics of the Sierra Leone conflict. It is important to note that, on average, the youth in our sample had spent more than five years with the Revolutionary United Front (RUF). The RUF were well-known for their brutality and harsh techniques of indoctrination and suppression, particularly in their treatment of child soldiers. Given this context, any former child soldier who made it through the war alive likely developed and relied upon a number of survival strategies to navigate such a harsh and dangerous environment. Some of these young people, particularly those who survived abuse, may actually possess a sense of resourcefulness that is exhibited in improved confidence and sense of agency over time. Indeed, many of the items measured in the confidence subscale capture such dynamics (e.g., feeling calm under pressure, confident in doing things on one's own, etc.).

In our qualitative data, prosocial behaviors, particularly the efforts of former child soldiers to be kind to others and have positive interactions were described as a means of signaling to others that a young person was not a threat or morally corrupt. As a female former child soldier explained: "My parents accepted me .but other people in the community [did] not understand.... I later mingled with them [after that they] have observed that I am not a bad person.... I was very kind to everybody and we started to do things in common."

Our finding of a significant relationship between a younger age of abduction and increased levels of depression over time aligns with recent developmental science indicating that exposure to toxic stress may be most damaging during sensitive periods in a child's development (National Scientific Council on the Developing Child, 2005; Shonkoff \& Phillips, 2000). In addition, the lack of association between length of time with the fighting forces and any of the psychosocial outcomes (adjusted for severe violence exposures) indicates that severe violence exposures, rather than absolute length of abduction, are most important for predicting psychosocial adjustment over time. 


\section{Protective Factors and Mental Health Adjustment}

Just as the presence of distinct toxic exposures must be considered in identifying which waraffected youth are most at risk for poor psychosocial adjustment, the presence of certain protective processes must also be evaluated. Consistent with research on the psychosocial benefits of school participation for children affected by armed conflict (Betancourt, 2005; Elbedour et al., 1993; Loughry et al., 2006; Sommers, 2003), we found that staying in school was associated with improved prosocial attitudes and behaviors. In the Sierra Leonean context, failure to find a greater protective effect of school retention on negative mental health outcomes such as anxiety, depression and hostility may be due to poor quality schools and the limited availability of psychosocial supports in the present education system. Despite the fact that Sierra Leone's secondary schools serve a cohort of youth whose lives were deeply affected by the war, very few secondary schools offer teacher salaries that lead to quality teaching, let alone time, training or staff to provide support and guidance for traumatized children (Betancourt, Simmons et al., 2008).

\section{The Mitigating Effect of Community Acceptance}

Overall, community acceptance emerged from our analysis as an important predictor of reduced depression over time as well as improvements in prosocial attitudes and confidence. These findings are consistent with other research pointing to community acceptance as an important factor in understanding the long-term reintegration of former child soldiers (Allen \& Schomerus, 2006; Boyden \& de Berry, 2004; Bracken \& Petty, 1998). Importantly, the influence of community acceptance was found to have a protective effect (Luthar et al., 2000) on depression and an enhancing effect on confidence and prosocial attitudes of former child soldiers regardless of whether they had a history of the most severe violence exposures or not. This finding speaks to the importance of post-conflict efforts to sensitize communities and encourage community acceptance of former child soldiers. In return, it appears that when former child soldiers experience improvements in community acceptance, they may return the gesture with increased positive effort (i.e., helping others, sharing, initiating activities). This finding speaks further to the agency of war-affected youth who, despite exposure to some of the most horrendous experiences of war, may make an extra effort to be helpful and kind to others when the larger community projects a willingness to accept them.

Overall, our study identified only a few protective factors that might assist the recovery of former child soldiers who have experienced the most severe and cumulative forms of war trauma. In fact, the magnitude of the effects of war-related stressors, particularly surviving rape and being involved in killing, were much larger than those associated with protective factors such as staying in school and experiencing improvements in community acceptance. Our finding that the stress-adjustment effects in this sample are generally weaker than the stress accumulation effects has important public health implications. It suggests that we have a long way to go before being able to fully mitigate the effects of particularly toxic stressors such as rape and involvement in killing in the lives of war-affected youth.

In future research, the search for additional sources of protection must be broadened to consider other forms of protection and support. It is also remains important to evaluate the influence of access to traditional healing resources as well as more formal clinical interventions in this population. Despite the severe stressors characterizing some former child soldiers, it is important to note that there has yet to be a rigorous evaluation of interventions addressing the influence of such traumatic events (nor post-conflict aftereffects such as stigma) on child mental health and development. 
Overall, our findings indicate no justification for an approach to targeting services at waraffected youth based on simple labels such as "former child soldiers" without individualized assessment. Although perpetration of killing and rape were important risk factors in our sample, these exposures did not characterize the majority of the sample. However, for youth with accumulated exposures to the most toxic forms of violence, access to rehabilitative services, such as clinical mental health treatment or other traditional approaches to healing may be some of the few pathways forward.

Further longitudinal research is necessary in order to truly disentangle the processes involved in the psychosocial adjustment of former child soldiers, the effects of extreme war exposures and their relationship to protective processes over time. In future research, more information is needed about the functions of family and peer relations as resources and supports as well as potential sources of continued strain in the process of reintegration. Beyond retention in school, the degree to which former child soldiers have been involved in other skills training programs, income-generating activities, and the degree to which they have access to other mentors or positive peers must be examined.

\section{Limitations}

A number of limitations are involved in the present study. First of all, an inherent challenge within cross-cultural research is studying constructs in nonwestern settings, where local notions of family or community acceptance are likely to be shaped by local context (Canino \& Alegria, 2008; Honwana, 2006; Matias-Carrelo et al., 2003). To ensure cultural relevance, we addressed these challenges through gathering additional qualitative data about the constructs of interest as well as consulting local staff members and others working with waraffected youth. Although many of the constructs we studied, such as family and community acceptance have particular relevance to Sierra Leone, to a large degree these constructs mirror mainstream theory about indicators of acceptance which have been used in prior research on the reintegration of adult soldiers following conflicts such as Vietnam (King et al., 1998)

Further, the sensitive nature of the data collected may be affected by response bias, particularly for difficult events such as rape and perpetration of killing. Previous research with survivors of violence has suggested that errors in reporting violent experiences, particularly in underreporting, may derive from deliberate strategies on the part of study participants to keep violent events secret in an effort to avoid retribution, future harm or stigma (Guterman \& Cameron, 1997; Guterman et al., 2000). It is possible that this is the case in our sample, especially for the reporting of rape and perpetration, which would likely result in underestimations of the relationships examined in this study.

In addition, age of the child and the time between the violent event and the time of reporting are also important factors to consider (Brandt et al., 2005; Guterman et al., 2000; Tajima et al., 2004). In general, younger children (preschool age) tend to have a harder time accurately reporting violent events that may have happened to them (Tajima et al., 2004). However, in our data, these concerns are reduced somewhat by the fact that the respondents were adolescents reporting on experiences with violence only two years after the end of the war; thus, their reporting bias may be more akin to adult responses in similar situations.

The lack of baseline data on pre-war mental health problems among youth in Sierra Leone limits our ability to compare the indicators of psychosocial adjustment observed in this sample to the general population. In addition, the challenge of identifying and retaining an appropriate comparison group remains one of the most persistent challenges in conducting research of this nature. Due to the dynamics of the war, it is impossible to identify a group of youth comparable to this cohort who did not experience some degree of exposure to war- 
related violence. Although our study design initially included a comparison group, the loss to follow-up in this group between $\mathrm{T} 1$ and $\mathrm{T} 2$ was too great to allow for reliable comparisons, a challenge that we intend to remediate in future stages of this research.

Finally, because our sample represents a cohort of youth demobilized over a specified time period rather than a regionally representative sample, our findings are limited in their ability to be generalized nationally. However, because our sample draws from more than four districts in Sierra Leone, we have no reason to believe that findings from this sample are not reflective of dynamics observed in other parts of the country.

\section{Implications}

It is important to consider the findings presented here in light of the current situation of social and mental health services for war-affected youth in Sierra Leone. At present, policymakers in Sierra Leone and the international community are focused on economic development and stability for the country. However, a failure to address the consequences of the war on Sierra Leone's young generation threatens the development of human capital and the investments being made in education and youth employment schemes (Mac-Ikemenjima, 2008). Our finding of a progressive deterioration over time in the adjustment of the most highly traumatized former child soldiers, contributing to increased levels of hostility for those who had killed, and increased anxiety and hostility among rape survivors, is of particular concern. Although rape survivors demonstrate more complexity in their response to war (manifest in greater risk for mental distress, but also a capacity for improved confidence and prosocial attitudes), those with a history of killing show only negative outcomes with time. In Sierra Leone, it is important to note that a number of programs have evolved to attend to the consequences of rape and other forms of gender-based violence, however very little attention has been given to addressing the mental health consequences of perpetrating atrocities. Certainly research from other wars has indicated that such experiences have profound developmental consequences and pose persistent risks for mental health problems (Davison et al., 2006; Grossman, 1996; King \& King, 1999).

Without more targeted attention to support these young people to make the best of the opportunities available to them in development efforts, the risks facing this particularly vulnerable cohort are likely to become more intractable. Such lost opportunity will have personal consequences for the youth in question, a compelling enough reason to act on human rights grounds alone. However, failure to truly address such long-term challenges to true reintegration and rehabilitation could very well have broader socio-political and security consequences for the society and country at large.

Unfortunately, many DDR programs operating internationally are hampered by inadequate funds to address the social services needs of war-affected youth and families in sustainable ways. Secondly, the funding streams, technical assistance, human resources developed during the initial humanitarian emergency and DDR period have not translated into sustainable systems of care. Although significant efforts were made in Sierra Leone's DDR efforts to provide assistance to former child soldiers in the immediate post conflict period, very few social or mental health services for war-affected youth of any kind remain today. With good reason, recent policy efforts have been cautious to rely on labeling or the targeting of only certain groups (such as former child soldiers) for services. However, in the attempt to avoid a focus on psychopathology or the singling out of specific groups for care in isolation of others, the reality of the residual trauma that some of these youth face has been minimized. As our data indicate, despite the dangers of labeling, there is an alarming concentration of particularly toxic risk factors among a portion of former child soldiers. Failing to ensure long-term monitoring, assessment and follow-up of these particularly highrisk groups, avoids the issue. 
In conclusion, the present study contributes to the scant literature on the experiences of child soldiers globally by providing the first prospective longitudinal data on a cohort of males and females. It is our hope that this and future research can enhance our scientific understanding of the processes linking war-related traumas to psychological functioning and raise awareness among local governments and the international community of the importance of investing in reasonable, effective and sustainable responses to support the mental health needs of all war-affected children.

\section{Acknowledgments}

We are endlessly grateful to all the local research assistants who carried out these interviews in Sierra Leone and our field-based project coordinators, Moses Zombo and Nassrin Farzaneh, who supervised the teams in 2002 and 2004. We are extremely indebted to Lloyd Feinburg, John Williamson, and Cathy Savino of USAID's Displaced Children and Orphans Fund (DCOF). In addition, we are grateful to our colleagues at the International Rescue Committee, including Jane Warburton and Jodi Nelson and many others who helped this project to succeed along the way. In particular, we would like to thank Catherine Weisner whose leadership was essential for launching the first wave of data collection. We would like to thank Laura Nolan, Kate Ittleman and Harlyn Sidhu who helped compile and prepare the tables presented in this paper and Julia Rubin Smith who coordinated our Boston-based team. We would also like to thank Dr. Maggie Alegria of Harvard Medical School for her review of previous versions of this manuscript, Dr. Garrett Fitzmaurice of McLean Hospital for his excellent statistical advice and Sidney Atwood and Kathy McGaffigan for their tremendous skill in data management and analyses. This work was funded by USAID's Displaced Children and Orphan's Fund. The present publication was also supported by Grant \# 1K01MH077246-01A2 from the National Institute of Mental Health.

\section{References}

Achenbach, TM.; Rescorla, LA. Multicultural understanding of child and adolescent psychopathology: Implications for mental health assessment. The Guilford Press; New York: 2006.

Alexander, J. Community based reintegration: Programme Evaluation. UNICEF; 2006.

Allen, T.; Schomerus, M. A hard homecoming: Lessons learned from the reception center process in northern Uganda. Management Systems International; Washington D.C.: 2006.

Annan, J.; Blattman, C.; Carlson, K.; Mazurana, D. The state of female youth in northern Uganda: Findings from the survey of war-affected youth. UNICEF; 2008.

Annan, J.; Blattman, C.; Horton, R. The state of youth and youth protection in northern Uganda. UNICEF; 2006.

Ashby P. Child combatants: a soldier's perspective. Lancet 2002;360(9350):s11. [PubMed: 12504484]

Barenbaum J, Ruchkin V, Schwab-Stone M. The psychosocial aspects of children exposed to war: practice and policy initiatives. J Child Psychol Psychiatry 2004;45(1):41-62. [PubMed: 14959802]

Bayer CP, Klasen F, Adam H. Association of trauma and PTSD symptoms with openness to reconciliation and feelings of revenge among former Ugandan and Congolese child soldiers. JAMA 2007;298(5):555-559. [PubMed: 17666676]

Beckett C, Maughan B, Rutter M, Castle J, Colvert E, Groothues C, et al. Do the effects of early severe deprivation on cognition persist into early adolescence? Findings from the English and Romanian adoptees study. Child Development 2006;77(3):696-711. [PubMed: 16686796]

Betancourt TS. Stressors, supports and the social ecology of displacement: psychosocial dimensions of an emergency education program for Chechen adolescents displaced in Ingushetia, Russia. Cult Med Psychiatry 2005;29(3):309-340. [PubMed: 16404689]

Betancourt, TS.; Borisova, I.; Rubin-Smith, J.; Gingerich, T.; Williams, T.; Agnew-Blais, J. Psychosocial adjustment and social reintegration of children associated with armed forces and armed groups: The state of the field and future directions. Psychology Beyond Borders; Austin, TX: 2008.

Betancourt TS, Borisova I, Whitfield T, de la Soudiere M, Williamson J. Sierra Leone's child soldiers: war traumas and post-conflict psychosocial adjustment by gender. (in preparation).

Betancourt, TS.; Brewer, S.; De la Soudiere, M. Holding on to hope: Education, coping, and the struggles of children associated with fighting forces in Sierra Leone. A report to the International 
Rescue Committee Children and Youth Protection and Development Program. International Rescue Committee; 2005.

Betancourt TS, Khan KT. The mental health of children affected by armed conflict: Protective processes and pathways to resilience. Int Rev Psychiatry 2008;20(3):317-328. [PubMed: 18569183]

Betancourt, TS.; Pochan, S.; de la Soudiere, M. Psychosocial adjustment and social reintegration of child ex-soldiers in Sierra Leone: A follow-up analysis. International Rescue Committee; Freetown: 2005.

Betancourt TS, Simmons S, Borisova I, Brewer SE, Iweala U, de la Soudiere M. High hopes, grim reality: reintegration and the education of former child soldiers in Sierra Leone. Comparative Education Review 2008;52(4)

Blattman, C.; Annan, J. The consequences of child soldiering. The Institute of Development Studies: University of Sussex; Brighton: 2007.

Boothby, N. When former child soldiers grow up: The keys to reintegration and reconciliation. In: Boothby, N.; Strang, A.; Wessells, M., editors. A world turned upside down: Social ecological approaches to children in war zones. Kumarian Press, Inc; Bloomfield, CT: 2006.

Boothby N, Crawford J, Halperin J. Mozambique child soldier life outcome study: Lessons learned in rehabilitation and reintegration efforts. Global Public Health 2006;1(1):87-107. [PubMed: 19153896]

Boyden, J.; de Berry, J., editors. Children and youth on the front line: Ethnography, armed conflict and displacement. Berghahn Books; New York: 2004.

Bracken, P.; Petty, C., editors. Rethinking the trauma of war. Free Association Books; London: 1998.

Brandt R, Ward CL, Dawes A, Flisher AJ. Epidemiological measurement of children's and adolescents' exposure to community violence: Working with the current state of the science. Clinical Child \& Family Psychology Review 2005;8(4):327-342. [PubMed: 16362258]

Bronfenbrenner, U. The ecology of human development: Experiments by nature and design. The Harvard University Press; Cambridge, MA: 1979.

Burman ME, McKay S. Marginalization of girl mothers during reintegration from armed groups in Sierra Leone. International Nursing Review 2007;54(4):316-323. [PubMed: 17958659]

Canino G, Alegria M. Psychiatric diagnosis-is it universal or relative to culture? Journal of Child Psychology and Psychiatry 2008;49(3):237-250. [PubMed: 18333929]

Coalition to Stop the Use of Child Soldiers. Child soldiers: Global report 2004. Coalition to Stop the Use of Child Soldiers; London: 2004.

Coalition to Stop the Use of Child Soldiers. Child soldiers: Global report 2008. Coalition to Stop the Use of Child Soldiers; London: 2008.

Davison EH, Pless AP, Gugliucci MR, King LA, King DW, Salgado DM, et al. Late-life emergence of early-life trauma. Research on Aging 2006;28(1):84-114.

Derluyn I, Broekaert E, Schuyten G, De Temmerman E. Post-traumatic stress in former Ugandan child soldiers. Lancet 2004;363(9412):861-863. [PubMed: 15031032]

Dohrenwend, BS.; Dohrenwend, BP., editors. Stressful life events: Their nature and effects. Wiley; New York: 1974.

Elbedour S, Bensel R, Bastien DT. Ecological integrated model of children of war: Individual and social psychology. Child Abuse Negl 1993;17(6):805-819. [PubMed: 8287292]

Eyber, C.; Ager, A. Poverty and displacement: Youth agency in Angola. In: Carr, S.; Sloan, T., editors. Community psychology and global poverty. Kluwer Academic Publishers; Dordrecht, The Netherlands: 2003.

Grossman, D. On killing: The psychological cost of learning to kill in war and society. Back Bay Books; 1996.

Guterman NB, Cameron M. Assessing the impact of community violence on children and youths. Social Work 1997;42(5):495-505. [PubMed: 9311306]

Guterman NB, Cameron M, Staller K. Definitional and measurement issues in the study of community violence among children and youths. Journal of Community Psychology 2000;28(6):571-587. 
Hatch SL, Dohrenwend BP. Distribution of traumatic and other stressful life events by race/ethnicity, gender, SES and age: a review of the research. American Journal of Community Psychology 2007;40(3-4):313-332. [PubMed: 17906927]

Hofmann SG, Litz BT, Weathers FW. Social anxiety, depression, and PTSD in Vietnam veterans. Journal of Anxiety Disorders 2003;17(5):573. [PubMed: 12941367]

Honwana, A. Child soldiers in Africa. University of Pennsylvania Press; Philadelphia, PA: 2006.

Hundt GL, Chatty D, Thabet AA, Abuateya H. Advocating multi-disciplinarity in studying complex emergencies: the limitations of a psychological approach to understanding how young people cope with prolonged conflict in Gaza. Journal of Biosocial Science 2004;36(4):417. [PubMed: 15293384]

Johnson K, Asher J, Rosborough S, Raja A, Panjabi R, Beadling C, et al. Association of combatant status and sexual violence with health and mental health outcomes in postconflict Liberia. JAMA 2008;300(6):676-690. [PubMed: 18698066]

King DW, King LA. Post-traumatic stress disorder in a national sample of female and male Vietnam veterans: Risk. Journal of Abnormal Psychology 1999;108(1):164. [PubMed: 10067002]

King LA, King DW, Fairbank JA, Keane TM, Adams GA. Resilience-recovery factors in posttraumatic stress disorder among female and male Vietnam veterans: Hardiness, postwar social support, and additional stressful life events. Journal of Personality and Social Psychology 1998;74(2):420-434. [PubMed: 9491585]

Kohrt, B. Recommendations to promote psychosocial well-being of children associated with armed forces and armed groups (CAAFAG) in Nepal. UNICEF; 2007.

Kohrt BA, Jordans MJD, Tol WA, Speckman RA, Maharjan SM, Worthman CM, et al. Comparison of mental health between former child soldiers and children never conscripted by armed groups in Nepal. JAMA 2008;300(6):691-702. [PubMed: 18698067]

Layne, CM.; Warren, JS.; Watson, PJ.; Shalev, AY. Risk, vulnerability, resistance, and resilience. In: Friedman, MJ., editor. Handbook of PTSD. The Guilford Press; New York: 2007. p. 497-520.

Lazarus, RS.; Folkman, S. Psychological stress and the coping process. Springer; New York, NY: 1984.

Loughry M, Ager A, Flouri E, Khamis V, Hamid AH, Qouta S. The impact of structured activities among Palestinian children in a time of conflict. Journal of Child Psychology and Psychiatry 2006;47(12):1211-1218. [PubMed: 17176376]

Lustig SL, Kia-Keating M, Knight WG, Geltman P, Ellis H, Kinzie JD, et al. Review of child and adolescent refugee mental health. J Am Acad Child Adolesc Psychiatry 2004;43(1):24-36. [PubMed: 14691358]

Luthar S, Cicchetti D, Becker B. The construct of resilience: A critical evaluation and guidelines for future work. Child Development 2000;71(3):543-562. [PubMed: 10953923]

Luthar SS, Goldstein A. Children's exposure to community violence: Implications for understanding risk and resilience. Journal of Clinical Child \& Adolescent Psychology 2004;33(3):499-505. [PubMed: 15271607]

Mac-Ikemenjima D. Youth development, reintegration, reconciliation and rehabilitation in postconflict West Africa: A framework for Sierra Leone, Liberia and Cote d'Ivoire. International NGO Journal 2008;3(9):146-151.

Machel, G. Impact of armed conflict on children. United Nations; 1996.

Machel, G. The impact of war on children. Hurst \& Company; London: 2001.

Macksoud MS, Aber JL. The war experiences and psychosocial development of children in Lebanon. Child Development 1996;67(1):70-88. [PubMed: 8605835]

MacMullin C, Loughry M. Investigating psychosocial adjustment of former child soldiers in Sierra Leone and Uganda. Journal of Refugee Studies 2004;17(4):460-472.

Maguen, S.; Suvak, M.; Litz, BT.; Adler, AB.; Castro, CA.; Britt, TW. Predictors and prevalence of post-traumatic stress disorder among military veterans. Praeger Security International; Westport, CT: 2006.

Masten AS, Obradovic J. Disaster preparation and recovery: Lessons from research on resilience in human development. Ecology and Society 2008;13(1):1-16. 
Matias-Carrelo LE, Chavez LM, Negron G, Canino G, Aguilar-Gaxiola S, Hoppe S. The Spanish translation and cultural adaptation of five mental health outcome measures. Cult Med Psychiatry 2003;27(3):291-313. [PubMed: 14510096]

Mazurana, D.; Carlson, K. The girl child and armed conflict: Recognizing and addressing grave violations of girls' human rights. United Nations; 2006.

Mazurana D, Khristopher C. From combat to community: Women and girls of Sierra Leone. 2004

Mazurana, D.; McKay, S. Girls in fighting forces in northern Uganda, Sierra Leone, and Mozambique: Policy and program recommendations. Canadian International Development Agency; 2003.

McEwen BS. Allostasis and allostatic load: implications for neuropsychopharmacology. Neuropsychopharmacology 2000;22(2):108-124. [PubMed: 10649824]

McKay, S.; Mazurana, D. Where are the girls? Girls in fighting forces in Northern Uganda, Sierra Leone, and Mozambique: Their lives during and after war. International Center for Human Rights and Democratic Development; Montreal: 2004.

McKay, S.; Robinson, M.; Gonsalves, M.; Worthen, M. Girls formerly associated with fighting forces and their children: Returned and neglected. Coalition to Stop the Use of Child Soldiers; London: 2006.

National Committee for Demobilisation Disarmament and Reintegration. Final Report of the Truth and Reconciliation Commission of Sierra Leone. Children and the armed conflict in Sierra Leone, Chapter 4 2004;3b

National Scientific Council on the Developing Child. The Center on the Developing Child at Harvard University; 2005. Excessive stress disrupts the architecture of the developing brain: Working Paper \#3.

Nelson CA 3rd, Zeanah CH, Fox NA, Marshall PJ, Smyke AT, Guthrie D. Cognitive recovery in socially deprived young children: the Bucharest Early Intervention Project. Science 2007;318(5858):1937-1940. [PubMed: 18096809]

Netland M. Event-list construction and treatment of exposure data in research on political violence. Journal of Traumatic Stress 2005;18(5):507-517. [PubMed: 16281249]

Peters K, Richards P. Why we fight: Voices of youth combatants in Sierra Leone. Africa 1998;68(2): 183-215.

Raghunathan TE, Lepkowski JM, Van Hoewyk J, Solenberger P. A mulitvariate technique for multiply imputing missing values using a sequence of regression models. Survey Methodology 2001;27(1): 85-95.

Rubin, DB. Multiple imputation for nonresponse in surveys. Wiley \& Sons; New York: 1987.

Rutter, M. Implications of resilience concepts for scientific understanding. In: Lester, B.; Masten, A.; McEwen, B., editors. Resilience in children: Annals of the New York Academy of Sciences. Vol. 1094. Blackwell; 2006.

Rutter M, Pickles A, Murray R, Eaves L. Testing hypotheses on specific environmental causal effects on behavior. Psychological Bulletin 2001;127(3):291-324. [PubMed: 11393298]

Santacruz ML, Arana RE. Experiences and psychosocial impact of the El Salvador civil war on child soldiers. Biomedica 2002;22(Supplement 2):283-397.

SAS Institute Inc. SAS (Version 9.1.2). Cary, North Carolina: 2004.

Shepler S. The rites of the child: Global discourses of youth and reintegrating child soldiers in Sierra Leone. Journal of Human Rights 2005;4(2):197-211.

Shonkoff, JP.; Phillips, DA., editors. From neurons to neighborhoods: The science of early childhood development. National Academy Press; Washington, D.C.: 2000.

Smyke AT, Koga SF, Johnson DE, Fox NA, Marshall PJ, Nelson CA, et al. The caregiving context in institution-reared and family-reared infants and toddlers in Romania. J Child Psychol Psychiatry 2007;48(2):210-218. [PubMed: 17300560]

Sommers, M. Education in emergencies. Creative Associates International; Washington, DC: 2003.

Tajima EA, Herrenkohi TI, Huang B, Whitney SD. Measuring child maltreatment: A comparison of prospective parent reports and retrospective adolescent reports. American Journal of Orthopsychiatry 2004;74(4):424-435. [PubMed: 15554804]

The World Revolution. Child soldiers: A global problem. 2001 
Thoits PA. On merging identity theory and stress research. Social Psychology Quarterly 1991;54(2): 101-112.

UNICEF. Guide to the optional protocol on the involvement of children in armed conflict. UNICEF; New York: 2003.

UNICEF. The disarmament, demobilization and reintegration of children associated with the fighting forces: Lessons learned in Sierra Leone. UNICEF; 2005.

UNICEF. Paris principles: Principles and guidelines on children associated with armed forces or armed conflict. UNICEF; New York: 2007.

Weiss, D.; Marmar, C. The Impact of Event Scale-Revised. In: Keane, T., editor. Assessing psychological trauma and PTSD. Guilford; New York: 1997.

Wessells M. Child soldiers, peace education, and postconflict reconstruction for peace. Theory Into practice 2005;44(4):363-369.

Wessells, MG. Child soldiering: Entry, reintegration, and breaking cycles of violence. In: Fitzduff, M.; Stout, C., editors. The psychology of resolving global conflicts: From war to peace. Vol. 3. Praeger Security International; Westport, CT: 2006. p. 243-266.

Williamson, J. Reintegration of child soldiers in Sierra Leone: January 31-February 9, 2005. US Agency for International Development; 2005.

Worthman CM, Panter-Brick C. Homeless street children in Nepal: Use of allostatic load to assess the burden of childhood adversity. Development and Psychopathology 2008;20(1):233-255.

[PubMed: 18211736] 


\section{Table 1}

Socio-Demographic Characteristics of the Sample

\begin{tabular}{|c|c|}
\hline Characteristic & $\mathrm{M} / \mathrm{N}(\mathrm{SD} / \%)$ \\
\hline Age at Interview T1, y & $15.13(2.25)$ \\
\hline \multicolumn{2}{|l|}{$\operatorname{Sex} a$} \\
\hline Male & $137(88 \%)$ \\
\hline \multicolumn{2}{|l|}{ Religion, T1 } \\
\hline Christian & $79(53 \%)$ \\
\hline Muslim & $70(47 \%)$ \\
\hline \multicolumn{2}{|l|}{ Literacy, T1 } \\
\hline Poor & $73(50 \%)$ \\
\hline Functional & $57(40 \%)$ \\
\hline Moderate & $15(10 \%)$ \\
\hline In school $b, \mathbf{T} 1$ & $107(72 \%)$ \\
\hline In school at $\mathrm{T} 1$ and $\mathrm{T} 2 c$ & $96(65 \%)$ \\
\hline Age of abduction, $y$ & $10.51(2.98)$ \\
\hline Length of time with armed forces, $y$ & $4.68(.73)$ \\
\hline Relative SES, T2 $($ Range $=4-16)$ & $9.39(2.28)$ \\
\hline \multicolumn{2}{|l|}{ Note: Ns $=143-156$} \\
\hline \multicolumn{2}{|l|}{${ }^{a}$ Coded " 0 " for boys and " 1 " for girls } \\
\hline
\end{tabular}




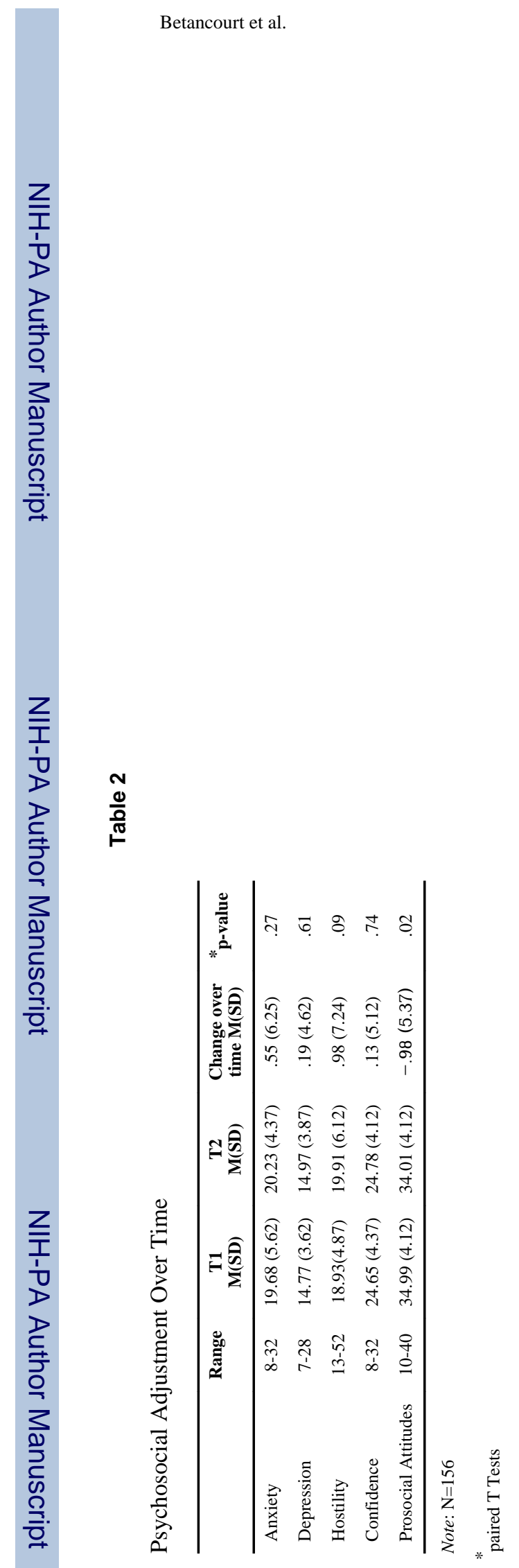

Child Dev. Author manuscript; available in PMC 2010 August 13. 


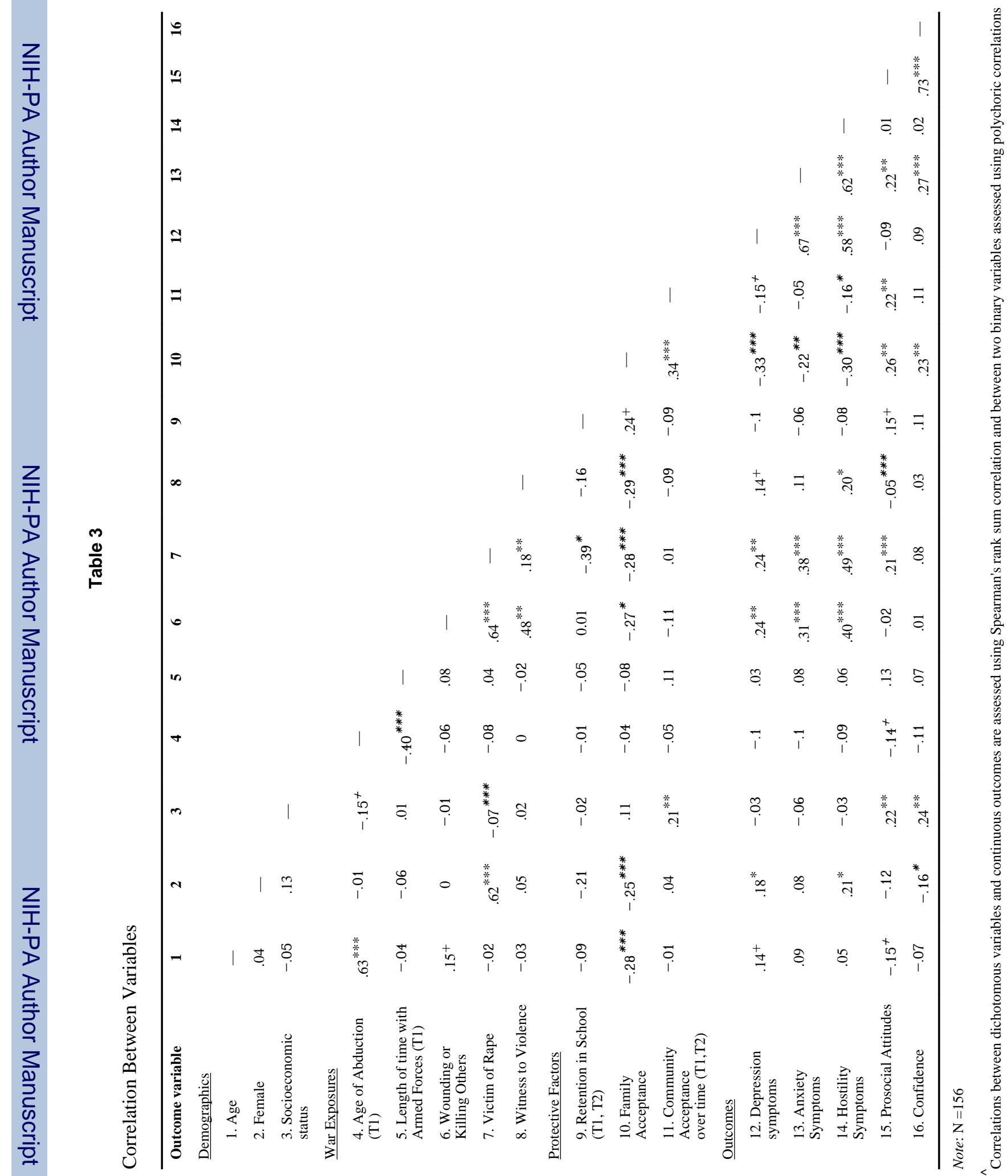




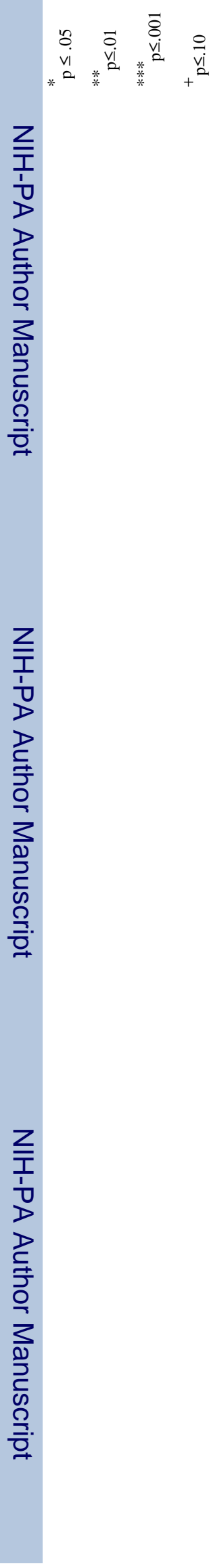




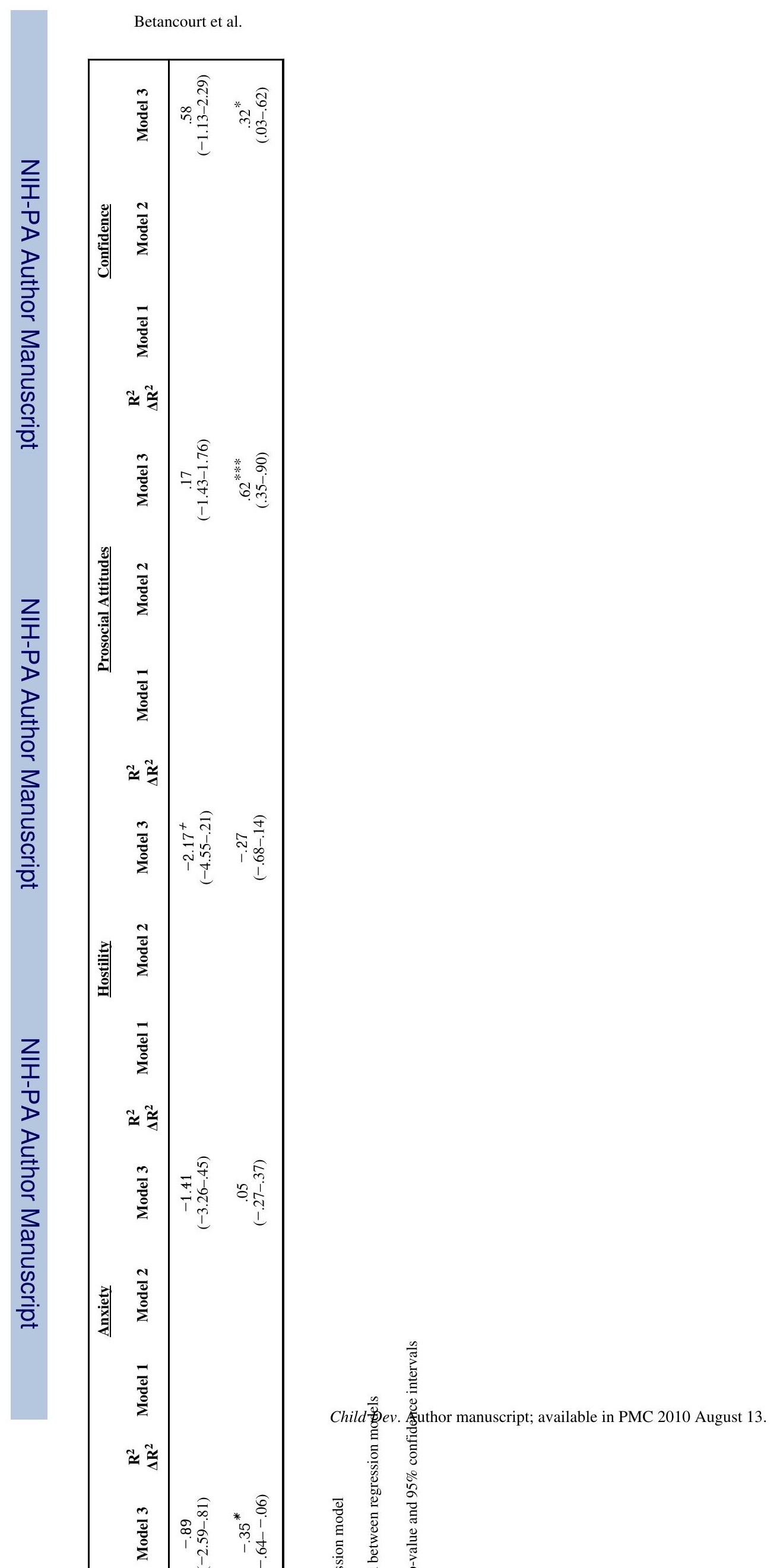

Page 28 